Revista Educação e Políticas em Debate - v. 10, n. 2, p. 801-818, mai./ago. 2021 - ISSN 2238-8346

\title{
O Programa de Demanda Social da Capes no contexto da pós-graduação brasileira
}

\author{
The Capes Demanda Social Program concerning graduation environment
}

Le programme "Demanda Social" de la "Capes" dans le contexte des masters et doctorats brésiliens

\author{
Patrícia Reis Paiva ${ }^{1}$ \\ Universidade Federal do Rio Grande do Sul \\ Nair Heloisa Bicalho de Sousa ${ }^{2}$ \\ Universidade de Brasília \\ Diogo Onofre Gomes de Souza ${ }^{3}$ \\ Universidade Federal do Rio Grande do Sul
}

\begin{abstract}
Resumo: O DS/Capes é o maior programa de bolsas de mestrado e doutorado stricto sensu acadêmico do Brasil. Em 2018, atendia 145 instituições de ensino superior públicas, 2.555 programas de pós-graduação e 53.168 cotas de bolsa. Este artigo busca propagar essa política pública por meio de sua descrição histórica, que se formalizou em 1976 e chegou a quadruplicar de tamanho. Para tanto, revisitou a legislação que dispôs sobre a concepção e as alterações dele, da Capes e da pós-graduação brasileira, de 1951 a 2019. Conclui-se que, apesar de oscilações decorrentes de fatores econômicos e políticoestratégicos, se manteve, conservou sua representatividade entre outros programas e demonstrou ser bem-sucedido em seu objetivo de formar recursos humanos de alto nível de diferentes áreas do conhecimento.
\end{abstract}

Palavras-chave: Demanda Social. Políticas Públicas. Ensino Superior. Mestrado. Doutorado.

Abstract: The "DS/Capes" is the biggest Brazilian grant program related to master and doctorate degrees. In 2018, attended 145 public higher education institutions, 2.555 graduate programs and 53.168 scholarships. This paper aims to disseminate this public policy by describing its history, which formally begun in 1976 and reached four times its size. Therefore, revisited the legislation about the conception and changes of this program, "Capes" and Brazilian graduation, from 1951 to 2019. In conclusion, despite of oscillation resulting from economic and strategic political factors, it remained firm, preserved its representation among other programs and succeed its central purpose which is to form high quality of human resources in different knowledge areas.

\footnotetext{
1 Mestre em Política Social pela Universidade de Brasília (UnB). Analista em Ciência e Tecnologia da Coordenação de Aperfeiçoamento de Pessoal de Nível Superior (Capes) e Doutoranda no Programa de PósGraduação em Educação em Ciências: Química da Vida e Saúde da Universidade Federal do Rio Grande do Sul (UFRGS). E-mail: patriciarpaiva82@gmail.com. Lattes: http://lattes.cnpq.br/2979405564870512. ORCID: https://orcid.org/O000-0001-5338-7286.

2 Doutora em Sociologia pela Universidade de São Paulo (USP). Docente do Departamento de Serviço Social da Universidade de Brasília (UnB). E-mail: nair.bicalho@gmail.com. Lattes: http://lattes.cnpq.br/0737170964136460. ORCID: https://orcid.org/0000-0001-8268-7210.

${ }^{3}$ Doutor em Bioquímica pela Universidade Federal do Rio de Janeiro (UFRJ). Docente do Instituto de Ciências Básicas da Saúde da Universidade Federal do Rio Grande do Sul (UFRGS). E-mail: diogo@ufrgs.br. Lattes: http://lattes.cnpq.br/9534019126486839. ORCID: https://orcid.org/0000-0002-4322-0404.
} 
Keywords: Demanda Social. Public Policy. Higher Education. Masters. Doctorate degree.

Résumé: Le programme DS/Capes est le plus grand programme de bourses de masters et de doctorats académiques au Brésil. En 2018, il a bénéficié 145 établissements publics d'enseignement supérieur et 2555 programmes d'études supérieures (masters et doctorats) avec 53.168 quotas de bourses. Cet article vise à propager cette politique publique à travers de sa description historique, qui a été officialisée en 1976 et a quadruplé de taille. À cette fin, il a revisité la législation qui prévoyait sa conception et aussi la évolution du programme, de la Capes e des courses de master et de doctorat brésiliennes de 1951 à 2019 . Il est conclu que, malgré les oscillations résultant de facteurs économiques et politique-stratégiques, il a conservé sa représentativité parmi d'autres programmes et s'est avéré être un succès dans son objectif de former des personelles de haut niveau issues de différents domaines de connaissances.

Mots clés: Le programme "Demanda Social”. Politique publique. Études supérieures. Master. Doctorat.

Recebido em: 18 de maio de 2020

Aceito em: 30 de dezembro de 2020

\section{Introdução}

Em momentos de restrição orçamentária, como o que se instaurou após a promulgação da Emenda Constitucional $\mathrm{n}^{\circ}$ 95, de 15 de dezembro de 2016 (BRASIL, 2016), a qual estabeleceu o Novo Regime Fiscal e limitou o teto de gastos sociais federais até 2036, faz-se ainda mais necessário analisar as políticas públicas existentes para, então, defender sua permanência ou aprimoramento.

Ahlert (2003, p. 130) apresenta as políticas públicas como “ações empreendidas pelo Estado para efetivar as prescrições constitucionais sobre as necessidades da sociedade em termos de distribuição e redistribuição das riquezas, dos bens e serviços sociais". Também as classifica enquanto resultado do "jogo de poder determinado por leis, normas, métodos e conteúdos” (Ibid.). No campo das políticas públicas educacionais, ocorre a mesma disputa e interação.

Este trabalho se debruça sobre uma política específica de concessão de bolsas de mestrado e doutorado stricto sensu: o Programa de Demanda Social da Coordenação de Aperfeiçoamento de Pessoal de Nível Superior (DS/Capes). O objetivo é colocar esse, que é o maior Programa com essas características, no centro do debate, a fim de demonstrar sua importância no contexto da pós-graduação brasileira. Em dezembro de 2018, estava atendendo 145 instituições de ensino superior públicas e gratuitas, 2.555 programas de 
Revista Educação e Políticas em Debate - v. 10, n. 2, p. 801-818, mai./ago. 2021 - ISSN 2238-8346 pós-graduação avaliados com notas entre 3 e 5, e 53.168 cotas de bolsas, sendo 30.054 no mestrado e 23.114 no doutorado.

Por tratar de artigo histórico, o método utilizado é, essencialmente, de revisão documental relativa ao Programa DS/Capes, à Capes e à pós-graduação brasileira. Resgatouse a legislação pertinente, de 1951 a 2019, tais como decretos, leis, pareceres, relatórios e resoluções. Os gráficos contendo informações sobre o Programa DS/Capes foram elaborados por meio de consulta ao Sistema de Informações Georreferenciadas da Capes (Geocapes) e do cruzamento de dados do Coleta Capes (2010 a 2012), da Plataforma Sucupira (2013 a 2018) e do Sistema de Acompanhamento de Concessões (SAC) (2010 a 2018).

Para compreender esse programa, o qual forma profissionais e pesquisadores nas mais diversas áreas do conhecimento, em todo o país, serão mostrados seu alcance e trajetória decorrente do desenvolvimento da pós-graduação brasileira e da concessão de bolsas de estudo pela Capes. Por meio dessa descrição, que finda no ano de 2018, esperase propagar essa política pública de educação superior, que se adaptou, mesmo frente a mudanças econômicas e político-estratégicas.

\section{O Programa DS/Capes}

O Programa DS/Capes tem por objetivo a formação de recursos humanos de alto nível no país. Para tanto, celebra acordo com instituições de ensino superior (IES) públicas e de ensino gratuito que mantenham programas de pós-graduação (PPG) stricto sensu aprovados ou avaliados com notas entre 3 e $5^{4}$. Desse modo, reforça o acesso ao ensino superior e a qualificação de futuros profissionais, de forma a colaborar com uma saída da condição de pobreza e com uma diminuição das desigualdades sociais (YANNOULAS; GARCIA, 2017).

Esse programa passou por oscilações desde o registro oficial dos dados, a partir de 1995, de acordo informações extraídas do Sistema de Informações Georreferenciadas da Capes (Geocapes) $)^{5}$ e sintetizadas na Figura 1.

\footnotetext{
${ }^{4}$ Desde 1998, os PPG são avaliados periodicamente e classificados com notas entre 1 e 7 (BRASIL, 2011a, p. 32).

${ }_{5}^{5}$ Disponível em: https://geocapes.capes.gov.br/geocapes/. Acesso em: 9 out. 2020.
} 
Figura 1. Quantidade de cotas de bolsa concedidas no Programa DS/Capes, entre os anos de 1995 e 2018.

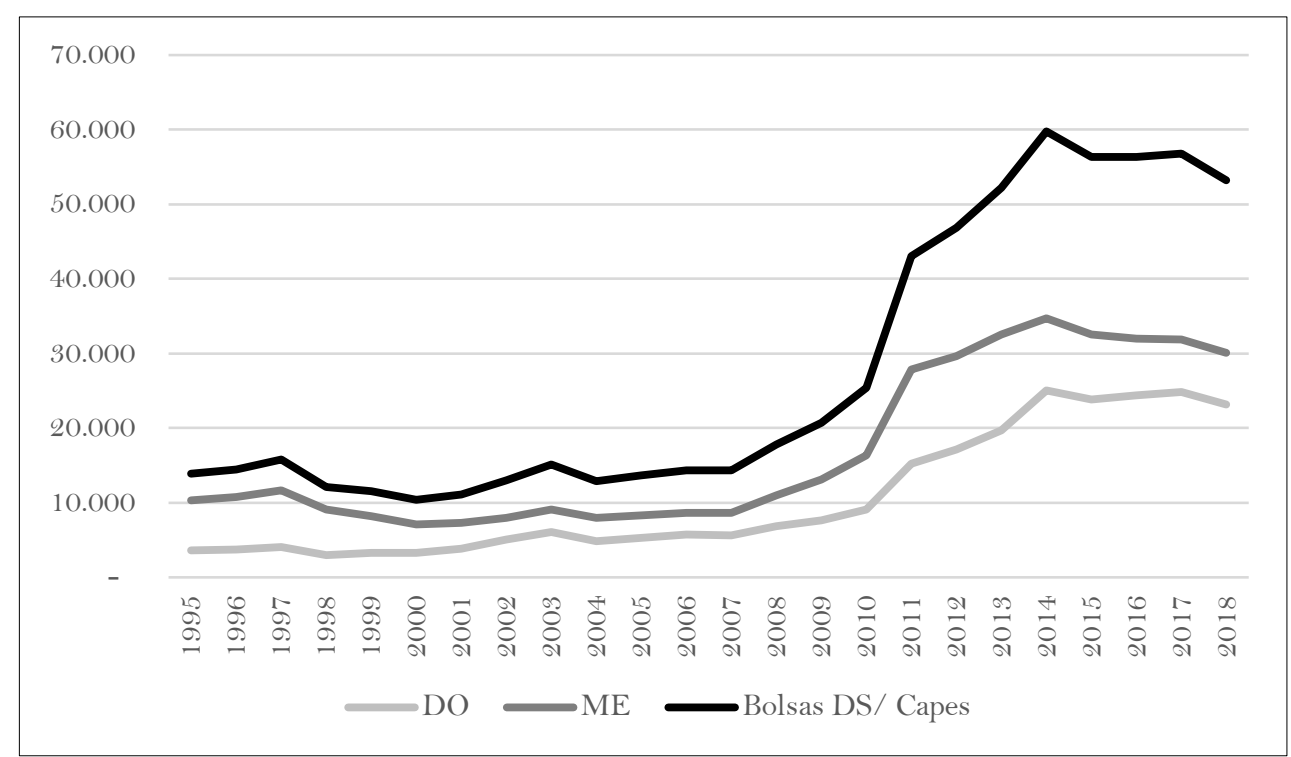

Fonte: Informação adaptada de dados do Sistema de Informações Georreferenciadas da Capes (Geocapes).

Ao longo desse período, a variação na quantidade de cotas de bolsa concedidas ocorreu tanto por fatores econômicos quanto por fatores político-estratégicos para a formação de novos programas ou incorporação de cotas de programas extintos ou advindas de concessões adicionais. Em relação à primeira queda, entre 1997 e 2000, no mês de novembro daquele ano, foram publicados os Decretos $\mathrm{n}^{\circ} 2.370$ e 2.401 (BRASIL, $1997 \mathrm{a}$, 1997b), os quais previam medidas de ajuste fiscal. As despesas com manutenção, renovação ou concessão de novas bolsas referentes ao ano de 1998 não poderiam ultrapassar $90 \%$ dos gastos realizados no ano anterior. Então, as cotas de bolsa do Programa DS/Capes que, em 1997, eram 15.742, chegaram a 12.068, em 1998. Continuaram caindo nos anos seguintes, atingindo 11.522 e 10.394, em 1999 e 2000, respectivamente.

Ainda no ano 2000, parte do público abrangido pelo Programa DS/Capes ganhou destaque e passou a ser tratado separadamente. As IES privadas, então, migraram para o Programa de Suporte à Pós-Graduação de Instituições de Ensino Particulares (PROSUP) . Desse modo, de 1999 para 2000, a concessão de cotas do programa DS/Capes caiu ao passo que a do PROSUP iniciou com 1.730. Fato semelhante aconteceu com os PPG avaliados com notas entre 6 e 7, em 2004, com a formação do Programa de Excelência Acadêmica (PROEX)7.

\footnotetext{
${ }^{6}$ Para maiores informações: https://www.gov.br/capes/pt-br/acesso-a-informacao/acoes-e-programas/bolsas/bolsasno-pais/programa-de-suporte-a-pos-graduacao-de-instituicoes-de-ensino-particulares-prosup. Acesso em: 14 out. 2020. ${ }_{7}$ Para maiores informações: https://www.gov.br/capes/pt-br/acesso-a-informacao/acoes-e-programas/bolsas/bolsasno-pais/proex. Acesso em: 14 out. 2020.
} 
Revista Educação e Políticas em Debate - v. 10, n. 2, p. 801-818, mai./ago. 2021 - ISSN 2238-8346 A transição para o PROEX foi marcada com concessão inicial de 3.846 cotas, paralela à redução de 15.150 para 12.854 das cotas do Programa DS/Capes, entre os anos de 2003 e 2004.

A partir de 2004, com exceção da suave queda entre 2006 e 2007, o cenário mudou. A Lei Orçamentária Anual mais créditos para bolsas no país quase sextuplicou, de $\mathrm{R} \$ 384.726 .818,00$, em 2004, para R \$2.302.458.091,00, em 2014, conforme Tabela 1. Esse aumento repercutiu no apoio de outros programas específicos, como será mencionado na última seção.

Tabela 1. Evolução das dotações orçamentárias previstas para a Capes, bolsas de estudo e bolsas no país, no período de 2004 a 2018.

\begin{tabular}{cccc}
\hline Ano & Dotação total da Capes $(\mathrm{R} \$)$ & $\begin{array}{c}\text { Dotação de bolsas } \\
\text { de estudo }(\mathrm{R} \$)\end{array}$ & $\begin{array}{c}\text { Dotação de bolsas no país } \\
(\mathrm{R} \$)\end{array}$ \\
\hline 2004 & $579.474 .551, \mathrm{OO}$ & $485.945 .802, \mathrm{OO}$ & $384.726 .818, \mathrm{OO}$ \\
2005 & $677.458 .680, \mathrm{OO}$ & $550.327 .273, \mathrm{OO}$ & $401.640 .791, \mathrm{OO}$ \\
2006 & $750.956 .994, \mathrm{OO}$ & $600.197 .811, \mathrm{OO}$ & $453.860 .64 \mathrm{O}, \mathrm{OO}$ \\
2007 & $833.479 .174, \mathrm{OO}$ & $659.202 .722, \mathrm{OO}$ & $477.478 .949, \mathrm{OO}$ \\
2008 & $1.275 .548 .817, \mathrm{OO}$ & $872.224 .111, \mathrm{OO}$ & $569.316 .507, \mathrm{OO}$ \\
2009 & $1.927 .926 .074, \mathrm{OO}$ & $1.343 .855 .772, \mathrm{OO}$ & $789.667 .384, \mathrm{OO}$ \\
2010 & $2.591 .938 .210, \mathrm{OO}$ & $1.808 .770 .166, \mathrm{OO}$ & $868.801 .241, \mathrm{OO}$ \\
2011 & $3.036 .937 .415, \mathrm{OO}$ & $1.808 .770 .166, \mathrm{OO}$ & $1.158 .452 .243, \mathrm{OO}$ \\
2012 & $3.891 .578 .913,00$ & $2.953 .942 .256, \mathrm{OO}$ & $1.655 .517 .621, \mathrm{OO}$ \\
2013 & $5.301 .022 .392, \mathrm{OO}$ & $4.389 .519 .469, \mathrm{OO}$ & $2.128 .625 .521, \mathrm{OO}$ \\
2014 & $6.073 .808 .814,00$ & $5.183 .415 .048, \mathrm{OO}$ & $2.302 .458 .091, \mathrm{OO}$ \\
2015 & $7.433 .665 .299, \mathrm{OO}$ & $6.624 .625 .944, \mathrm{OO}$ & $2.210 .295 .672, \mathrm{OO}$ \\
2016 & $5.904 .999 .740, \mathrm{OO}$ & $5.034 .440 .884, \mathrm{OO}$ & $2.408 .027 .763, \mathrm{OO}$ \\
2017 & $4.959 .308 .757, \mathrm{OO}$ & $3.976 .221 .281, \mathrm{OO}$ & $2.661 .546 .983, \mathrm{OO}$ \\
2018 & $3.844 .645 .259,00$ & $3.042 .039 .931, \mathrm{OO}$ & $2.055 .156 .792, \mathrm{OO}$ \\
\hline
\end{tabular}

Fonte: Informação adaptada da Lei Orçamentária Anual (LOA) mais créditos ${ }^{8}$.

Uma das atribuições da Capes é definir a concessão anual de bolsas, em observação à disponibilidade orçamentária do Ministério da Educação. Essa concessão depende da previsão orçamentária, para o ano seguinte, estabelecida na Lei Orçamentária Anual (LOA). De acordo com Salvador e Teixeira (2014, p. 17), “os gastos orçamentários definem a direção e a forma

\footnotetext{
8 “Orçamento - Evolução em reais”. Disponível em: https://www.gov.br/capes/pt-br/acesso-ainformacao/institucional/orcamento-evolucao-em-reais. Acesso em: 14 out. 2020.
} 
Revista Educação e Políticas em Debate - v. 10, n. 2, p. 801-818, mai./ago. 2021 - ISSN 2238-8346 de ação do Estado nas suas prioridades de políticas públicas”. Tratam de decisão políticoestratégica, fruto de disputa por recursos.

O aumento da dotação orçamentária, no período de 2004 a 2014, impactou diretamente as bolsas do programa DS/Capes, que mais que quadruplicaram (de 12.854 para 59.770). Esse crescimento se intensificou entre os anos de 2010 e 2011 , quando a concessão mudou de 25.423 para 43.102 bolsas, devido ao aumento de recursos e a outra série de ações. A primeira delas foi a migração de bolsas do Programa de Fomento à Pós-Graduação (PROF) ${ }^{9}$, extinto em 2011, por meio da Portaria n 215 (BRASIL, 2011b). No ano anterior (2010), o quantitativo de cotas de bolsas desse programa era de 8.412. A segunda ação também correspondeu à migração, mas devido à descontinuidade do Programa Reestruturação e Expansão das Universidades Federais (Reuni) ${ }^{10}$. Esse programa iniciou a concessão de bolsas em 2008 e a finalizou em 2012. A partir de janeiro de 2013, as cotas de bolsa canceladas por motivo de titulação ou término de vigência passaram a ser atendidas pelos programas DS/Capes ou PROEX, a depender da nota do PPG.

Outras ações que colaboraram para o aumento de cotas do programa DS/Capes foram as iniciativas relativas a concessões adicionais. A mais expressiva aconteceu com o Bolsa Para Todos (BPT), que concedeu, entre os anos de 2009 a 2011, cerca de 19.000 bolsas de mestrado e doutorado a IES atendidas pelos programas DS/Capes e PROF, nas regiões Norte, Nordeste, Centro-Oeste e Sul, entre 2009 e 201 1, visando corrigir assimetrias regionais ${ }^{11}$. A partir de 2011 , jovens medalhados nas Olimpíadas Brasileiras de Matemática das Escolas Públicas (OBMEP) puderam ganhar uma bolsa de mestrado ou doutorado no Programa DS/Capes devido ao acordo firmado entre a Capes e o Instituto de Matemática Pura e Aplicada (IMPA), que formou o Programa de Iniciação Científica e Mestrado (PICME) ${ }^{12}$. Além disso, de 2013 a 2018, passou-se a conceder 2 cotas de mestrado e 4 de doutorado para cursos novos em funcionamento ${ }^{13}$.

Existiram outras concessões adicionais pontuais, entre elas, no período de abril de 2013 a abril de 2015, PPG que enviassem discentes para realização de estágio no exterior por um período mínimo de 9 meses recebiam concessão de bolsas de doutorado, visando estimular a internacionalização ${ }^{14}$. Por fim, entre 2012 e 2014, foram concedidas cotas adicionais com base

\footnotetext{
${ }_{9}^{9}$ Programa que concedia bolsas de mestrado e doutorado a 12 instituições federais de ensino superior.

10 Programa que buscava ampliar o acesso e a permanência no ensino superior. No âmbito da Capes, concedia bolsas de mestrado, doutorado e pós-doutorado. Para maiores informações, ver relatórios de gestão, separados por ano, em Processos de Contas Anuais, disponíveis em: https://www.gov.br/capes/pt-br/acesso-ainformacao/prestacao-de-contas-anuais. Acesso em: 14 out. 2020.

${ }^{11}$ Para maiores informações, ver relatórios de gestão, conforme nota $\mathrm{n}^{\mathrm{o}} 10$.

${ }^{12} \mathrm{Id}$.

${ }_{13} \mathrm{Id}$.

14. Id.
} 
Revista Educação e Políticas em Debate - v. 10, n. 2, p. 801-818, mai./ago. 2021 - ISSN 2238-8346 na utilização de cotas pelos PPG, priorizando o doutorado e cursos em fase de consolidação (criados a partir de 2011), conforme relatórios de gestão.

De 2014 para 2015, as bolsas do Programa DS/Capes decresceram de 59.770 para 56.354, mesmo com a manutenção de algumas iniciativas citadas, tais como incorporação progressiva de bolsas Reuni, PICME, cotas a cursos novos e bolsas para incentivo à internacionalização. Nota-se também um aumento tanto na dotação orçamentária total da agência (de $\mathrm{R} \$ 6.073 .808 .814,00$ para $\mathrm{R} \$ 7.433 .665 .299,00$ ) quanto nas bolsas de estudo (de $\mathrm{R} \$ 5.183 .415 .048,00$ para $\mathrm{R} \$ 6.624 .625 .944,00)$, conforme dados da Tabela 1. O decréscimo pode ser explicado pela concentração dos recursos no Programa Ciência Sem Fronteiras $(\mathrm{CsF})^{15}$, que teve um incremento de $\mathrm{R} \$ 1.383 .745 .040,00$, nesses anos.

Já de 2015 a 2017, ainda de acordo com dados da Tabela 1, houve uma leve retomada no crescimento do número de bolsas do Programa DS/Capes (de 56.354 para 56.379 e 56.804), mesmo com queda da dotação orçamentária de bolsas de estudo (de $\mathrm{R} \$ 6.624 .625 .944,00$ para $\mathrm{R} \$ 5.034 .400 .884,00$ e $\mathrm{R} \$ 3.976 .221 .281,00)$. Nesse período, as bolsas no país foram priorizadas, subindo a previsão de $\mathrm{R} \$ 2.210 .295 .672,00$ para $\mathrm{R} \$ 2.408 .027 .763,00$ e $\mathrm{R} \$ 2.661 .246 .983,00$. Em 2018, a redução da dotação total da Capes ocasionou redução da dotação de bolsas de estudo e, por consequência, de bolsas de estudo no país. De 2017 para 2018, a concessão do programa DS/Capes caiu de 56.804 para 53.168.

A tendencia é que esse quantitativo reduza ainda mais, principalmente devido ao Novo Regime Fiscal, cuja aplicação para a educação e a saúde passou a vigorar em 2018, com o orçamento base do ano de 2017. A EC nº5/2016 impacta diretamente a educação superior ao fixar gastos, que serão atualizados apenas pelo Índice Nacional de Preços ao Consumidor Amplo (IPCA) do ano anterior. Com isso, a manutenção da estrutura educacional deve ser prejudicada (CHAVES; REIS; GUIMARÃES, 2018; DUTRA; BRISOLLA, 2020).

Os fatores econômicos e político-estratégicos não foram os únicos que influenciaram as oscilações e o alcance do Programa DS/Capes. Poderia ser feita, por exemplo, uma análise detalhada sobre as últimas avaliações e os PPG que perderam bolsa desse programa por terem sido descredenciados ou terem melhorado de conceito (6 ou 7). Importa frisar que, dos últimos 23 anos, 16 foram de crescimento. No geral, o Programa DS/Capes cresceu de tamanho, atingindo 53.168 bolsas, em 2018. Em 1995, essas cotas correspondiam a 71,48\% das 19.425 bolsas de mestrado e doutorado concedidas por essa agência. Essa representatividade caiu até 2010, quando chegou a 45,97\%, mas retomou, no ano seguinte, com 63,04\%. Em 2018, finalizou com 57,77\%. A comparação entre o número de bolsas do Programa DS/Capes e demais

\footnotetext{
${ }_{15}^{15}$ Para maiores informações: http://cienciasemfronteiras.gov.br/web/csf/o-programa. Acesso em: 14 de out. 2020.
} 
Revista Educação e Políticas em Debate - v. 10, n. 2, p. 801-818, mai./ago. 2021 - ISSN 2238-8346 programas de bolsa de mestrado e doutorado no país ${ }^{16}$ dessa agência, no período entre 1995 e 2018, pode ser conferida na Figura 2.

Figura 2. Comparação entre a quantidade de cotas concedidas pelo Programa DS/Capes e outros programas no país da agência entre os anos de 1995 e 2018.

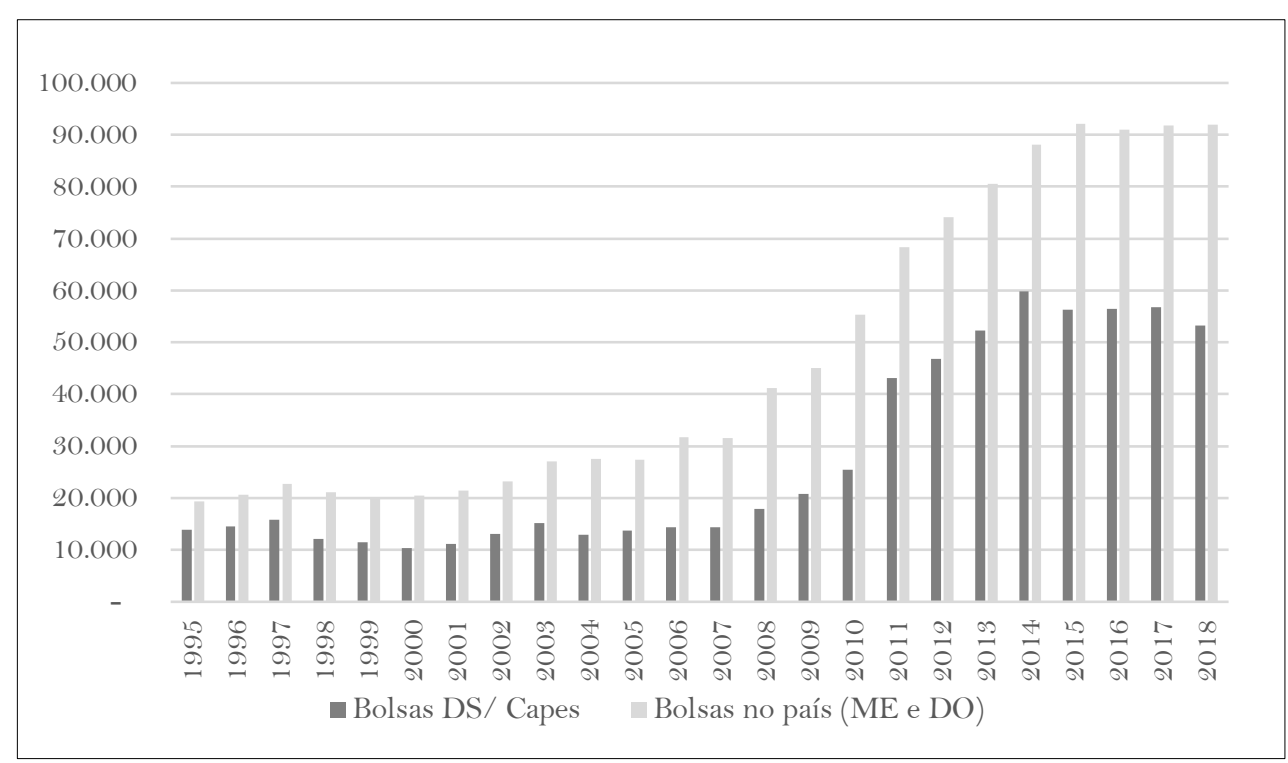

Fonte: Informação adaptada de dados do Sistema de Informações Georreferenciadas da Capes (Geocapes).

Esse alcance se torna mais relevante quando comparado com o número de titulados do Sistema Nacional de Pós-Graduação (SNPG). O Plano Nacional de Educação (PNE) (BRASIL, 2014) propôs, para o período de 2014-2024, a elevação gradativa do número de matrículas na pós-graduação stricto sensu, de modo a atingir a titulação anual de 60.000 mestres e 25.000 doutores. A meta 14 do PNE não está longe de ser plenamente alcançada. Em 2017, se titularam 50.306 no mestrado acadêmico e 10.841 no mestrado profissional, totalizando 61.147 nesse nível. Em 2018, esses números subiram para 51.610, 12.822 e 64.432, nessa ordem. Nesse mesmo ano, titularam-se 22.894 no doutorado acadêmico e 7 no doutorado profissional, totalizando 22.901.

Caso permaneçam algumas estratégias traçadas pelo PNE, tais como expansão do financiamento por meio das agências oficiais de fomento e da oferta de cursos de pós-graduação stricto sensu, é razoável supor que a meta seja atingida dentro do prazo. Ressalta-se, contudo, que a $\mathrm{EC} \mathrm{n}^{\circ}$ 95/2016 inviabiliza o pleno atendimento do PNE (DUTRA; BRISOLLA, 2020).

Para finalizar esta seção, cabe destacar a capacidade de formação desse programa da Capes. O percentual de titulação ultrapassa os $90 \%$, quando se considera os discentes que 

iniciaram a percepção de bolsa entre os anos de 2010 e 2012. Começa a cair a partir de 2013, principalmente por causa do doutorado, que exige, em média, 4 anos para conclusão. A partir desse ano, a concentração de bolsistas permanece como matriculada, ultrapassando $50 \%$ a partir de 2016 e chegando a 98\% em 2018, conforme Figura 3.

Figura 3. Comparação entre bolsistas do Programa DS/Capes matriculados, não titulados e titulados, nos anos de 2010 e 2018.

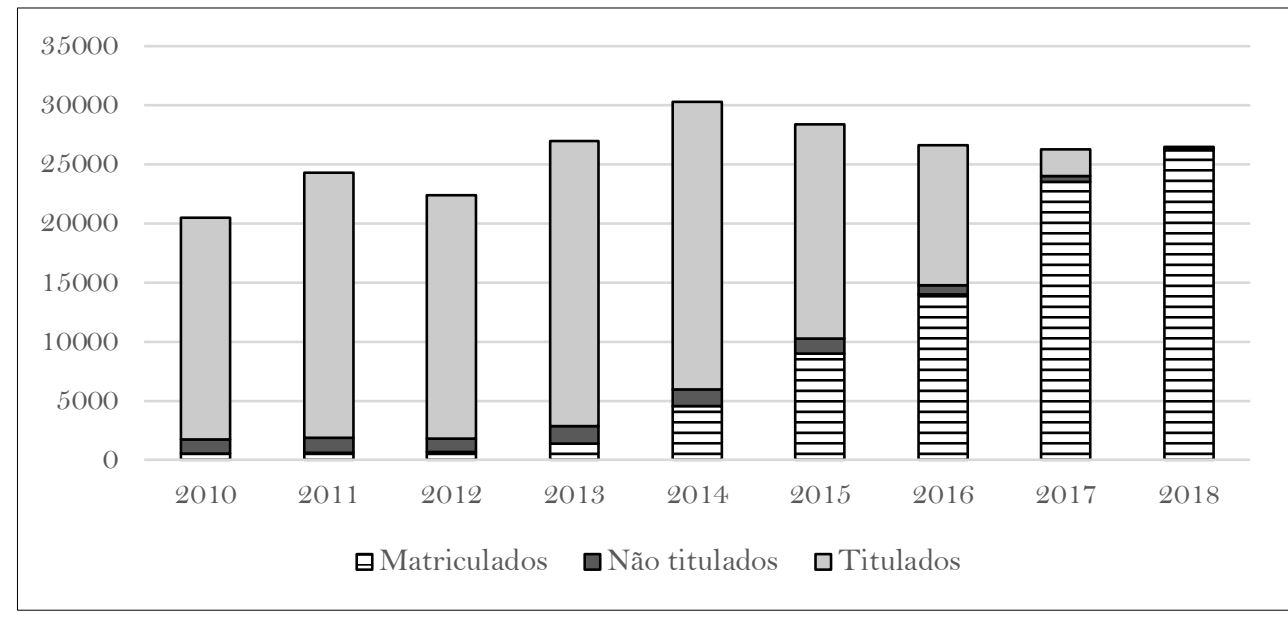

Fonte: Cruzamento de dados do Coleta Capes (2010 a 2012), da Plataforma Sucupira (2013 a 2018) e do Sistema de Acompanhamento de Concessões (2010 a 2018). Elaboração da autora.

Entre os anos de 2010 e 2018, dos 233.823 discentes que receberam bolsa, 142.635 (61\%) titularam e apenas 9.247 (3,95\%) evadiram. Para compreender como o Programa DS/Capes ganhou esse formato e dimensão, é preciso entender sua trajetória, que está inserida no histórico da Capes e da pós-graduação brasileira, a ser tratado na próxima seção.

\section{Formação e desenvolvimento da pós-graduação brasileira e da Capes}

A Pós-graduação brasileira é relativamente recente. No início da década de 1950, para atingir o projeto governamental de desenvolvimento e independência, intensificou-se a reflexão sobre a necessidade de formação de especialistas e pesquisadores (BRASIL, 2002, p. 17; 2011 a, p. 9). Em 11 de julho de 1951, por meio do Decreto no 29.741 (BRASIL, 1951), a Presidência da República instituiu uma Comissão sob a responsabilidade do Ministro da Educação e Saúde e composta por diversos membros do setor público, a fim de promover uma Campanha Nacional de Aperfeiçoamento de Pessoal de Nível Superior (Capes). Essa Campanha objetivava assegurar a existência de pessoal especializado em qualidade e quantidade, visando o desenvolvimento econômico e social, e oferecer aos indivíduos mais capazes, sem recursos próprios, acesso a oportunidades de aperfeiçoamento. Tal abertura 
Revista Educação e Políticas em Debate - v. 10, n. 2, p. 801-818, mai./ago. 2021 - ISSN 2238-8346 inaugura uma política de Estado que contribui com a construção de uma cidadania mais participativa e democrática. A educação resgata "valores humanitários como a solidariedade, a consciência do compromisso para com o bem-estar de todos, a fraternidade e a reciprocidade" (AHLERT, 2003, p. 144).

O desenvolvimento da pós-graduação se intensificou, principalmente, a partir da década de 1960 (BRASIL, 2002, p.34, 202, 298). O primeiro marco legal surgiu com a Lei de Diretrizes e Base de 1961 (BRASIL, 1961), a qual lançou dispositivos em relação à educação nacional, citando a pós-graduação como categoria de curso do ensino superior, sem a detalhar. Essa indeterminação ensejou a publicação do Parecer nº 977 de 1965, conhecido como Parecer Sucupira (BRASIL, 1965), cujo conteúdo propunha preencher essa lacuna, definindo a natureza e balizando a organização desses cursos (BRASIL, 2002, p.300). Em 27 de novembro de 1968 foi publicada a Lei ${ }^{\circ} 5.539$ (BRASIL, 1968), cujo teor vinculava a admissão em cargo de auxiliar de ensino superior à aprovação em curso de pós-graduação. Por meio do Parecer $n^{\circ} 77 / 1969$ (BRASIL, 1969) do Conselho Federal de Educação, foram finalmente determinadas as normas para o credenciamento desses cursos e validação dos diplomas emitidos.

Em seguida, na década de 1970, a preocupação com a rápida multiplicação dos cursos estimulou a instituição do Conselho Nacional de Pós-Graduação, no Ministério da Educação e Cultura, por meio do Decreto $n^{\circ}$ 73.411, de 4 de janeiro de 1974 (BRASIL, 1974). Esse conselho tinha como uma de suas atribuições a execução e atualização da Política Nacional de PósGraduação, além da elaboração do Plano Nacional de Pós-Graduação (PNPG). O primeiro plano (BRASIL, 1975a) foi publicado no ano seguinte e ficou vigente até 1979. Teve como diretrizes a elevação dos padrões de desempenho, o planejamento da expansão e a institucionalização do sistema de pós-graduação. Essa institucionalização foi uma das grandes contribuições do PNPG e repercutiu na forma de repasse de recursos da Capes ${ }^{17}$, migrando dos indivíduos para as instituições (BRASIL, 2002, p. 73, 80, 127). Assim, passaram a ser celebrados convênios globais com as instituições em vez de concessão de bolsas individuais aos candidatos. Essa alteração buscou tanto evitar a fragmentação dos investimentos quanto estimular a criação de setores responsáveis pela pós-graduação em cada universidade (Ibid., p. 74). Também permitiu acelerar o processo de concessão de bolsas e flexibilizar a distribuição das mesmas (BRASIL, 1976b, p. 14).

A partir desse momento, as Pró-Reitorias de Pós-Graduação passaram a fazer o trabalho que antes era executado por grupos acadêmicos isolados (BRASIL, sd.). Tornaramse os interlocutores entre a Capes e as instituições de ensino (CAPES, 2002, p. 74, 112, 187,

\footnotetext{
17 A partir do Decreto n53.932, de 26 de junho de 1964 (BRASIL), a Capes passou de Campanha para Coordenação, reunindo em um único órgão a Comissão Supervisora do Plano dos Institutos (COSUPI) e o Programa de Extensão do Ensino Tecnológico (PROTEC).
} 
Revista Educação e Políticas em Debate - v. 10, n. 2, p. 801-818, mai./ago. 2021 - ISSN 2238-8346 302), com atribuições de controle, seleção, pagamento e prestação de contas (BRASIL, 1975c, p. $3 ; 1977$, p. 6). Como novos e atuantes participantes, possibilitam "construir alternativas para uma educação pública e universal de qualidade mediante políticas educacionais democraticamente decididas e elaboradas” (AHLERT, 2003, p. 146).

Ainda na década de 1970, houve um grande salto de atuação da Capes, quando foi instituído o processo de avaliação dos programas de pós-graduação (PPG). A primeira ocorreu em 1976, com ênfase na pesquisa e no julgamento dos pares (MAGALHÃES; REAL, 2018). A partir da década de 1980, serviu como critério para distribuição de bolsas (BRASIL, 2011 a, p. 5, 32). Acredita-se que um dos motivos para o sucesso da pós-graduação brasileira é justamente o vínculo entre nota, número de bolsas e auxílio financeiro a programas (BRASIL, 2002, p. 93, 186, 178), pois corresponde a um critério objetivamente determinado. Tanto a avaliação da pós-graduação stricto sensu e os investimentos na formação de recursos de alto nível continuam compondo as linhas de ação dessa agência ${ }^{18}$.

Segundo o recurso executado no ano de 2018, seguindo a dotação prevista no Plano Plurianual 2016-201919, 79,24\% do orçamento dessa fundação (R\$3.040.610.837 de $\mathrm{R} \$ 3.837 .301 .197$ ) foram destinados para a concessão de bolsas de estudo. A dotação de bolsas no país (R $\$ 2.053 .727 .698)$ correspondeu a $67,54 \%$ das bolsas e $53,52 \%$ do total do recurso. Embora possa ser precipitado avaliar a importância dessa atividade apenas pelo viés orçamentário, não se pode ignorar que, devido ao dispêndio volumoso de recursos públicos, os programas de concessão de bolsas no país merecem especial atenção. Analisar o cumprimento de finalidades e a execução de estratégias programáticas pode conduzir à melhor gestão dos mesmos e ao atingimento de resultados sociais mais efetivos.

\section{Concessão de bolsas da Capes e o Programa DS/Capes}

A primeira atuação da Capes em relação à concessão de bolsa tratou do Serviço de Bolsas de Estudo (SBE), que realizava atividades de recrutamento e seleção de bolsistas, além de coleta e divulgação de informações sobre bolsas concedidas por outras entidades, tais como embaixadas, órgãos públicos e privados (CORDOVA, 1998, p. 43-44). Em 1952, foram ofertadas somente 3 bolsas, sendo 1 no país, na área de música, e 2 no exterior, nas áreas de agronomia e antropologia (Ibid., p. 44). Em 1953, esse número saltou para 79, sendo 25 no país e 54 no exterior (BRASIL, 2011a, p. 45).

\footnotetext{
18 "História e missão". Disponível em: https://www.gov.br/capes/pt-br/acesso-a-informacao/institucional/historia-emissao. Acesso em: 14 out. 2020.

${ }_{19}$ Ver nota $n^{\circ} 11$.
} 
Ainda em 1953, foram implantados dois programas. O Programa Universitário apoiava projetos voltados a centros, núcleos ou unidades de trabalho universitárias por meio da contratação de professores sêniores e promoção de missões universitárias (CORDOVA, 1998, p. 37). O Programa dos Quadros Técnicos e Científicos desenvolvia estudos, pesquisas, levantamentos e atendimentos individuais (Ibid., p. 40, 43).

Na década de 1960 e início de 1970, a qualificação docente fazia parte central do debate sobre a pós-graduação (BRASIL, 2002, p. 51). A fim de elevar os padrões de desempenho, o IPNPG especificou, como diretriz, programas institucionais de capacitação de docentes (BRASIL, 1975a, p.136). Assim, as instituições concentrariam esforços na melhoria de seus recursos humanos, com a finalidade de preencher áreas deficientes e abrir áreas novas em seus programas de ensino e pesquisa (Ibid., p. 138). O exemplo mais emblemático partiu de uma experiência piloto, entre os anos de 1974 e 1975, com o programa de Capacitação Institucional de Docentes (CID), que forneceu 168 bolsas a 6 universidades (BRASIL, 1976b, p. 24). Em 1975, foi implementado o Programa Institucional de Capacitação de Docentes (PICD), que previa um sistema de planejamento de longa duração $(1975 / 1979)$ e teve aderência de 44 IES (Ibid.). Na década de 1990, passou a se chamar Programa Institucional de Capacitação Docente e Técnica (PICDT) e, em 1998, restringiu o apoio a instituições públicas (BRASIL, 2002, p. 221). Durou até a primeira gestão do professor Abílio Afonso Baeta Neves (1995-2003).

Outro elemento importante no debate do IPNPG era a institucionalização. Além do PICD, outro programa ganhou destaque, nesse contexto: o de Demanda Social. Ambos os programas firmavam convênios diretamente com as IES e exigiam a constituição de uma Pró-Reitoria de Pós-Graduação como interlocutora nas relações com a Capes (BRASIL, 1977, p.6; 2002, p. 74, 112, 138, 302). Devido à essa obrigação, pode-se afirmar que atuaram como grandes colaboradores para a implantação e consolidação da pósgraduação no Brasil (BRASIL, 2002, p. 74).

Embora os dois Programas capacitassem a nível de mestrado e doutorado, no país, a Demanda Social aparecia mais como uma forma de diferenciação do PICD (BRASIL, 1976a, p.16). Visava alunos recém egressos de pós-graduação (BRASIL, 1975b, p. 2), independente de sua vinculação ao sistema de ensino superior, que poderiam "ter futuramente engajamento acadêmico ou de qualquer outra natureza” (BRASIL, 1977, p. 9). O surgimento exato do Programa DS/Capes é impreciso. Alguns discursos afirmam que teria iniciado com a fundação da Capes, em 1951 (BRASIL, 2011a, p. 23). Outros comentam sobre sua tradição e funcionamento anterior à década de 1970 (BRASIL, 1976a, p. 16; 1977, p. 9). Contudo, por meio de registros documentais da Capes, tais como atas de reuniões e relatórios gerenciais do 
Revista Educação e Políticas em Debate - v. 10, n. 2, p. 801-818, mai./ago. 2021 - ISSN 2238-8346 Conselho Técnico-Administrativo (CTA), bem como resoluções, é possível reconstruir essa história a partir de 1975 (BRASIL, 2002, p. 217-218).

A primeira vez que aparece o nome "Demanda Social" dentro da modalidade Bolsas de Estudos no País foi na resolução $n^{\circ} 58$, datada de 30 de dezembro de 1975, em que se aprovou o Plano de Trabalho do Programa de Bolsas de Estudos, para o ano de 1976. A previsão orçamentária era de Cr\$42.588.000 (BRASIL, 1975c, p. 295). No relatório referente ao ano de 1975, aprovado pelo CTA, em 09 de junho de 1976 (BRASIL, 1976b), somente constava o nome PICD dentro da categoria Programa de Estudos e Subprograma de Bolsas no País. Nas planilhas anexas do anexo 2 (Ibid., p. 35 a 51), descrevia-se a "situação das bolsas novas e renovações em 1975”, sem citar nome de programas de apoio. Já no relatório referente ao ano de 1976, aprovado pelo CTA, em junho de 1977 (BRASIL, 1977), a "Demanda Social” aparece junto com o PICD dentro de Programas de Bolsas de Estudo. Então, é possível afirmar que, a partir de 1976, o Programa DS/Capes passa a existir de fato (BRASIL, 1976a, p. 15; 2002, p. 219).

Algumas características gerais do programa permaneceram iguais, tais como intenção de formar recursos humanos e caráter institucional, por meio da gestão compartilhada. Outros atributos foram aprimorados ou desconsiderados ao longo do tempo. Importa ressaltar que independente da manutenção ou mudança, a concessão de bolsa deve estar atrelada a "um sistema coordenado de auxílio" (BRASIL, 2002, p.124).

É fato que o Programa DS/Capes não sobreviveria sem outras ações e programas complementares. Quanto às ações, constava a concessão de taxas acadêmicas e escolares, que eram auxílios associados às bolsas, mas que tinham por objetivo fomentar os PPG. As primeiras se destinavam à manutenção das atividades e serviços necessários ao desenvolvimento da programação acadêmica dos bolsistas. Duraram até 1997, quando foi criado o Programa de Apoio à Pós-Graduação (PROAP) ${ }^{20}$. As taxas escolares eram direcionadas às instituições privadas de ensino e cessaram em 2000, com a criação do PROSUP. Quanto aos programas complementares, o PROAP tem uma relação direta com o Programa DS/Capes, pois tem como pré-requisito a existência de cota de bolsa nesse programa da Capes. Outros programas que não estão vinculados diretamente à concessão de bolsa, mas que agregam valor à pós-graduação, são o Programa de Apoio a Eventos no País (PAEP) e o Portal de Periódicos ${ }^{21}$.

\footnotetext{
20 Para maiores informações: https://www.gov.br/capes/pt-br/acesso-a-informacao/acoes-e-programas/bolsas/bolsasno-pais/proap. Acesso em 14 out. 2020.

${ }^{21}$ Para maiores informações: https://www.gov.br/capes/pt-br/acesso-a-informacao/acoes-e-programas/bolsas/bolsasno-pais/paep e http://www.periodicos.capes.gov.br. Acesso em 14 out. 2020.
} 
Retomando o aspecto exclusivo de bolsa no país, por muito tempo permaneceram vigentes apenas o PICD/PICDT e o Programa DS/Capes. De acordo com dados do Geocapes a respeito de concessão de bolsas de pós-graduação da Capes no Brasil, até 1997 existiam somente os dois. Em 1998 e 1999, aparece o PROF. Em 2000 e 2001, são acrescentados o Programa de Cooperação Acadêmica em Defesa Nacional (PROCAD) e o PROSUP. Em 2002 surgem o Mestrado Interinstitucional (Minter) e o Programa de qualificação Institucional (PQI). Em 2003 aparecem outros programas específicos, mas, é a partir de 2004, que há uma separação estrutural dos programas tradicionais dos programas indutores e especiais (BRASIL, 2011a, p. 23).

Em 2009, há outra mudança relevante que impacta o Programa DS/Capes. Os valores das bolsas passam a ser pagos diretamente na conta bancária dos bolsistas, não passando mais pelas instituições, conforme relatório de gestão 2010.22 Por fim, a partir de 2010, há um grande crescimento do programa devido à incorporação de bolsas do PROF e REUNI e concessão adicional do BPT, além das ações de cota a cursos novos, conforme detalhado na seção 1. Esse volume fez com que o Programa DS/Capes se tornasse o maior apoiador de bolsas de mestrado e doutorado stricto sensu no Brasil. Devido a esse alcance e por tratar de benefícios concedidos a discentes de universidades públicas no país, contribui com o conceito de democracia participativa, que reafirma “a educação como um direito de todos os cidadãos” (ALHERT, 2003, p. 146)

\section{Considerações finais}

O Programa DS/Capes se iniciou no ano de 1976, em um cenário de ênfase institucional em vez de apoio individual de bolsistas. Também surgiu como alternativa à formação exclusiva de docentes, representado pelo PICD. Seguiu nos seus 42 anos de existência se adaptando aos novos desenhos e prioridades da pós-graduação brasileira e da Capes, bem como às incontingências financeiras vivenciadas por essa agência de fomento.

Ele estimulou a criação das pró-reitorias de pós-graduação, verdadeiras interlocutoras entre IES e Capes, além de partes essenciais na gestão compartilhada dos programas de bolsas. Colaborou com o sucesso da avaliação, que resulta em retirada ou concessão de cotas, a depender da nota recebida pelo programa de pós-graduação. Por fim, acompanhou o foco dado à pós-graduação stricto sensu.

No âmbito da Capes, manteve-se, mesmo com a retirada de benefícios que o integravam, como taxas acadêmicas, escolares e bolsas, para a formação dos programas específicos PROAP, PROSUP e PROEX. Por outro lado, incorporou bolsas dos programas

\footnotetext{
${ }^{22}$ Ver nota $n^{\circ} 11$
} 
Revista Educação e Políticas em Debate - v. 10, n. 2, p. 801-818, mai./ago. 2021 - ISSN 2238-8346 descontinuados PROF e Reuni. Além disso, recebeu concessões adicionais provindas do BPT, PICME, cursos novos e de outras ações pontuais.

Passou por oscilações no quantitativo de bolsas ofertado decorrentes, principalmente, por fatores econômicos. Em 1998, teve uma queda de 23,33\% devido a um pacote de ajuste fiscal. Em 2015, o decréscimo foi de 5,68\% pela priorização dada ao programa CsF. Em 2018, sofreu cortes na magnitude de 6,41\% por causa de restrições orçamentárias. No geral, entre os anos de 1995 e 2018, identificou-se um grande crescimento. O Programa DS/Capes praticamente quadruplicou de tamanho, chegando à oferta de 53.168 cotas, fruto do aumento da dotação de bolsas no país, fato que não deve se manter, principalmente devido à limitação imposta pela EC nº5/2016.

Embora outros programas tenham sido criados para atender demandas especiais e estratégicas, o programa em estudo conservou a alta representatividade, terminando o período em análise com 57,77\% das bolsas de mestrado e doutorado concedidas pela Diretoria de Programas e Bolsas no País (DPB/Capes). Pode-se afirmar que, mesmo frente a incertezas e mudanças, esse programa conseguiu cumprir seu objetivo principal de formação de recursos humanos, titulando 142.635 bolsistas que receberam o benefício a partir de 2010.

Desse modo, diante dos argumentos expostos acerca da capacidade de formação, de adaptação e de contribuição cidadã, reforça-se o importante papel que o Programa DS/Capes exerce perante a pós-graduação brasileira.

\section{Referências}

AHLERT, Alvori. Políticas públicas e educação na construção de uma cidadania participativa, no contexto do debate sobre ciência e tecnologia. Educere - Revista da Educação da UNIPAR, Umuarama, vol. 3, n. 2, p.129-148, jul./dez. 2003. Disponível em: https://revistas.unipar.br/index.php/educere/article/view/186. Acesso em: 4 jan. 2020. DOI: https://doi.org/10.25110/educere.v3i2.2003.186.

BRASIL. Decreto ${ }^{\circ}$ 2.370, de 10 de novembro de 1997a. Dispõe sobre a concessão de novas bolsas de estudo e de pesquisa no âmbito dos Ministérios da Educação e do Desporto e da Ciência e Tecnologia, no exercício de 1998, e dá outras providências. Disponível em: http://www.planalto.gov.br/ccivil 03/decreto/1997/D2370.htm. Acesso em: 20 out. 2020.

BRASIL. Decreto ${ }^{\circ}$ 2.401, de 21 de novembro de 1997b. Estabelece limites para o empenho da despesa e condições para a sua inscrição em restos a pagar, altera a redação do art. $1^{\circ}$ do Decreto $n^{o}$ 2.214, de 25 de abril de 1997, que dispõe sobre a compatibilização entre a realização da receita e a execução da despesa, sobre a programação orçamentária e financeira do Poder Executivo para o exercício de 1997, e dá outras providências. Disponível em: http://www.planalto.gov.br/ccivil_03/decreto/1997/D2401.htm. Acesso em: 20 out. 2020. 
Revista Educação e Políticas em Debate - v. 10, n. 2, p. 801-818, mai./ago. 2021 - ISSN 2238-8346

BRASIL. Decreto $\mathrm{n}^{\circ}$ 29.741, de 11 de julho de 1951. Institui uma Comissão para promover a Campanha Nacional de Aperfeiçoamento de pessoal de nível superior. Disponível em: https://www2.camara.leg.br/legin/fed/decret/1950-1959/decreto-29741-11-julho-1951336144-publicacaooriginal-1-pe.html. Acesso em: 20 out. 2020.

BRASIL. Decreto n ${ }^{\circ}$ 53.932, de 26 de maio de 1964. Reúne em um só órgão Capes, Cosupi e Protec. Disponível em: https://www2.camara.leg.br/legin/fed/decret/1960-1969/decreto53932-26-maio-1964-393973-publicacaooriginal-1-pe.html. Acesso em: 20 out. 2020.

BRASIL. Decreto $n^{\circ} 73.411$, de 4 de janeiro de 1974. Institui o Conselho Nacional de PósGraduação e dá outras providências. Disponível em:

https://www2.camara.leg.br/legin/fed/decret/1970-1979/decreto-73411-4-janeiro-1974421858-publicacaooriginal-1-pe.html. Acesso em: 20 out. 2020.

BRASIL. Emenda Constitucional n95, de 15 de dezembro de 2016. Altera o Ato das Disposições Constitucionais Transitórias, para instituir o Novo Regime Fiscal, e dá outras providências. Disponível em: http://www.planalto.gov.br/ccivil 03/constituicao/Emendas/Emc/emc95.htm. Acesso em: 3 jan. 2021.

BRASIL. Lei n ${ }^{\circ}$ 4.024, de 20 de dezembro de 1961. Fixa as Diretrizes e Bases da Educação Nacional. Disponível em: http://www.planalto.gov.br/ccivil_03/LEIS/L4024.htm. Acesso em: 20 out. 2020.

BRASIL. Lei $\mathrm{n}^{\circ}$ 5.539, de 27 de novembro de 1968. Modifica dispositivos da Lei número 4.881A, de 6 de dezembro de 1965, que dispóe sobre o Estatuto do Magistério Superior, e dá outras providências. Disponível em: https://www2.camara.leg.br/legin/fed/lei/1960-1969/lei5539-27-novembro-1968-359197-normaatualizada-pl.html. Acesso em: 20 out. 2020.

BRASIL. Lei $\mathrm{n}^{\circ}$ 13.005, de 25 de junho de 2014. Aprova o Plano Nacional de Educação - PNE e dá outras providências. Disponível em: http://www.planalto.gov.br/ccivil_03/_ato20112014/2014/lei/113005.htm. Acesso em: 20 out. 2020.

BRASIL. Ministério da Educação (MEC). Conselho Federal de Educação (CFE). Parecer no 77, aprovado em 11 de fevereiro de 1969. Documenta, n. 98, p. 128-132.

BRASIL. Ministério da Educação (MEC). Conselho Federal de Educação (CFE). Parecer no 977, aprovado em 3 de dezembro de 1965. Disponível em: http://cad.capes.gov.br/atoadministrativo-detalhar?idAtoAdmElastic $=314 \#$ anchor. Acesso em: 20 out. 2020.

BRASIL. Ministério da Educação do Brasil (MEC). Secretaria de Educação Superior (SESu/MEC)/Fundação Coordenação de Aperfeiçoamento de Pessoal de Nível Superior (Capes). I Plano Nacional de Pós-Graduação: 1975-1979, 1975a. Disponível em: https://www.gov.br/capes/pt-br/centrais-de-conteudo/i-pnpg-pdf. Acesso em: 20 out. 2020.

BRASIL. Ministério da Educação do Brasil (MEC). Secretaria de Educação Superior (SESu/MEC)/Fundação Coordenação de Aperfeiçoamento de Pessoal de Nível Superior (Capes). Relatório, Brasília, DF, [1986?]. 
BRASIL. Ministério da Educação (MEC). Fundação Coordenação de Aperfeiçoamento de Pessoal de Nível Superior (Capes). Ata da $\mathbf{1}^{\mathbf{a}}$. e $\mathbf{2}^{\mathbf{a}}$. sessões da $\mathbf{X}$ reunião do Conselho Técnico-Administrativo da Capes, 7 nov. 1975 b.

BRASIL. Ministério da Educação (MEC). Fundação Coordenação de Aperfeiçoamento de Pessoal de Nível Superior (Capes). Ata da $2^{\mathbf{a}}$. sessão da XIV reunião do Conselho Técnico-Administrativo da Capes, 16 ago. 1976a.

BRASIL. Ministério da Educação (MEC). Fundação Coordenação de Aperfeiçoamento de Pessoal de Nível Superior (Capes). Capes, 50 anos: depoimentos ao CPDOC/FGV. Organizadoras: FERREIRA, Marieta de Mores; MOREIRA, Regina da Luz, Brasília, DF, 2002. Disponível em: http://dominiopublico.mec.gov.br/pesquisa/DetalheObraForm.do?select_action=\&co_obra=246 33. Acesso em: 20 out. 2020.

BRASIL. Ministério da Educação (MEC). Fundação Coordenação de Aperfeiçoamento de Pessoal de Nível Superior (Capes). Capes 60 anos: Seis décadas de evolução da pós-graduação. Revista Comemorativa, Brasília, DF, jul., 2011 1a. Disponível em: https://www.gov.br/capes/pt$\mathrm{br} /$ centrais-de-conteudo/revista-capes-60-anos-pdf. Acesso em: 20 out. 2020.

BRASIL. Ministério da Educação (MEC). Fundação Coordenação de Aperfeiçoamento de Pessoal de Nível Superior (Capes). Portaria $n^{\circ} 215$, de $1^{\circ}$ de novembro de 2011 b. Disponível em: http:// cad.capes.gov.br/ato-administrativo-detalhar?idA toAdmElastic=672 \#anchor. Acesso em: 20 out. 2020.

BRASIL. Ministério da Educação (MEC). Fundação Coordenação de Aperfeiçoamento de Pessoal de Nível Superior (Capes). Relatório Capes de 1975, Brasília, DF, jun. 1976b.

BRASIL. Ministério da Educação (MEC). Fundação Coordenação de Aperfeiçoamento de Pessoal de Nível Superior (Capes). Relatório Capes de 1976, Brasília, DF, jun. 1977.

BRASIL. Ministério da Educação (MEC). Fundação Coordenação de Aperfeiçoamento de Pessoal de Nível Superior (Capes). Resolução no 26, de 9 de julho de 1975c. Brasília, DF, jul. 1975.

CHAVES, Vera Lúcia. J.; REIS, Luiz Fernando; GUIMARÃES, André R. Dívida Pública e financiamento da educação superior no Brasil. Acta Scientiarum. Education, Maringá, v.4O(1), e37668, 2018.

Disponível em: http://periodicos.uem.br/ojs/index.php/ActaSciEduc/article/view/37668. Acesso em: Acesso em: 4 jan. 2020. DOI: https://doi.org/10.4025/actascieduc.v40i1.37668.

CORDOVA, Rogério de A. CAPES: origem, realizações, significações (1951-1996). Brasília, DF, [s.n], 1998, vol. 1.

DUTRA, Norivan L. L.; BRISOLLA, Lívia S. Impactos e rupturas na educação superior brasileira após a Emenda Constitucional 95/2016: o caso dos institutos federais.

FINEDUCA - Revista de Financiamento da Educação, Porto Alegre, v. 10, n.7, 2020.

Disponível em: https://seer.ufrgs.br/fineduca/article/view/79581. Acesso em: 4 jan. 2021.

DOI: http://dx.doi.org/10.22491/fineduca-2236-5907-v10-79581. 
Revista Educação e Políticas em Debate - v. 10, n. 2, p. 801-818, mai./ago. 2021 - ISSN 2238-8346

MAGALHÃES, Ana Maria da S.; REAL, Giselle Cristina M. Situando os debates sobre a avaliação da pós-graduação: os estudos do campo pelo campo. EccoS - Revista Científica, São Paulo, n. 46, p. 131-148, 2018. Disponível em:

https://periodicos.uninove.br/eccos/article/view/7947. Acesso em: 20 out. 2020. DOI:

https://doi.org/10.5585/eccos.n46.7947.

SALVADOR, Evilasio; TEIXEIRA, Sandra O. Orçamento e políticas sociais: metodologia de análise na perspectiva crítica. Revista de Políticas Públicas, São Luís, v.18, n.1, p.15-32, jan./jun. 2014. Disponível em:

http://www.periodicoseletronicos.ufma.br/index.php/rppublica/article/view/2681. Acesso em: 4 jan. 2021 . DOI: http://dx.doi.org/10.18764/2178-2865.v18n1p15-32.

YANNOULAS, Silvia; GARCIA, Adir. A complexa relação entre educação, pobreza e desigualdade social. Em Aberto, Brasília, v. 30, n. 99, p.15-18, maio/ago. 2017. Disponível em: http://rbep.inep.gov.br/ojs3/index.php/emaberto/article/view/3197. Acesso em: 4 jan. 2020. DOI: https://doi.org/10.24109/2176-6673.emaberto.30i99.3331. 